\title{
Quality of Life Among Multiple Sclerosis Patients in Terms of Mental Health
}

\author{
Dima Ibrahim Abu Maloh ${ }^{1}$, Hazem Nouri AlNahar ${ }^{1} \&$ Haya Ibrahim Abu Maloh ${ }^{2}$ \\ ${ }^{1}$ Department Health and Recreation, Faculty of Physical Science, The University of Jordan, Amman, Jordan \\ ${ }^{2}$ Department of Nursing and Rehabilitation, Faculty of Medicine \& Health Sciences, Universiti Putra Malaysia \\ (UPM), 43400 UPM Serdang, Selangor, Malaysia \\ Correspondence: Dima Ibrahim Abu Maloh, Department Health and Recreation, Faculty of Physical Science, \\ The University of Jordan, Aljubeiha, Amman, Jordan. Tel: 96-27-9964-1044. E-mail: demamaloh@ gmail.com
}

Received: January 2, 2021

doi:10.5539/ass.v17n5p62
Accepted: April 7, $2021 \quad$ Online Published: April 27, 2021

URL: https://doi.org/10.5539/ass.v17n5p62

\begin{abstract}
This study aimed to identify the mental health quality of life among patients with multiple sclerosis in Jordan. Thus, a descriptive quantitative design was used on a total of $(\mathrm{N}=100)$ Multiple Sclerosis patients that were randomly selected by using convenience sampling from the Health Insurance Center in the capital Amman, Jordan. Outcome measurement tools were the demographic data form and the Multiple Sclerosis Quality of Life-54 (MSQOL-54) Scale. The demographic data form consisted of questions about: age in years, gender, stage of multiple scleroses, and physical activities. The Multiple Sclerosis Quality of Life-54 (MSQOL-54) consisted of two domains the physical health composite and the mental health composite. In this study the mental health composite were used by the participants. The results revealed that the QOL- Mental Health Composite among patients with multiple sclerosis was $33.9 \pm 33.6$. Moreover, there was no significant difference in score for male and females $\mathrm{p}=.874$. In addition, there was no significant difference in QOL mental health scores for the age groups $\mathrm{p}=.165$. Finally, there was a significant difference in scores for participants and non-participants in physical activity $\mathrm{p}=.000$. Accordingly, this research concluded that Multiple sclerosis patients' have a low quality of life in terms of mental health. In addition, practicing physical activities have a positive effect on the quality of mental health among multiple sclerosis patients.
\end{abstract}

Keywords: mental health, multiple sclerosis, quality of life

\section{Introduction}

Positive psychology is one of the recent psychological health concepts, which has received the attention of researches as it aims to achieve psychological health in individuals (Slade, 2010). Whereas the quality of life term is considered one of the most important topics in positive psychology fields because individuals face many psychological and social pressures in their life (Keyes et al., 2012). Therefore, the need for the concept of quality became more urgent in both physical and psychological aspects, which led to the interest of specialists in the quality of the life of the individual (Alkhulaifi, 2000).

The quality of life term is considered as a part of the medical terms used recently, whereas, it has been used regularly in the early eighties, it was used with oncology patients when doctors faced the problem of high cost of treating some diseases with the aim of increasing the life expectancy of these patients (Alhams, 2010). The quality of life has made an effective contribution to patient care, and is used to reflect the increasing respect and patient's satisfaction of the provided medical services (Asadi-Lari et al., 2004).

Although scientists differ in defining the quality of life and determining its dimensions, many of them agreed that the quality of life includes functional ability such as activity, psychological health, social harmony, and pathological symptoms and treatment (Kfafi \& Ala' Aldeen, 2006). Therefore, psychotherapists must focus in their treatment interventions and programs on the behavioral outcomes associated with these components (Cook et al., 2017).

Where Almarzouqi (2008) pointed out the importance of medical sociology, because when an individual suffers from the disease the quality of his life will be affected, so he feels depression and social isolation as a result of the change in his lifestyle, especially if he feels unable to carry out his daily activities normally. The more the 
surrounding does not understand the patient's condition, the worse the disease and the greater his suffering (Raune et al., 2004). Here comes the effective role of specialists in psychological and social counselling in improving the quality of the patients' lives to improve their psychological state, control the disease and increase the patient's acceptance of his disease, as well as give him hope in life (Bialuhina et al., 2017). The concept of psychological health is one of the terms that researchers and psychologists are most interested in as it is an important element for individuals, achieving it helps the individual to face different pressures and reach a happy life (Aldahri, 2005).

Among the diseases that a person can have is multiple sclerosis, as it is a chronic immune disease that affects the central nervous system (the brain and spinal cord), where the myelin responsible for transmitting nerve impulses and maintaining the health of nerves disappears (Compston et al., 2006). Nerve signals are very slow, and in the long term, the patient begins to face severe problems related to the functioning of some nerves, such as walking, speaking, muscle control, vision, writing and memory, and this disease often affects the age group between 20-40 years (Noseworthy et al., 2000).

The importance of studying the psychological disorders of multiple sclerosis patients is that the reported completed suicide rates are high, as psychological disorders are the main risk factor for suicide (Stenager et al., 1996), where reviews based on death certificates indicate that the death rate of multiple sclerosis patients due to suicide is $15 \%$ (Sadovnick et al., 1991). Through retrospective analyses of completed suicides of Multiple Sclerosis patients, depression is the main factor of suicide (Feinstein, 1997) and the anxiety and self-mutilation connected with suicidal intentions (Korostil \& Feinstein, 2007). Social isolation, the history of previous suicide attempts, and recent career decline of the patient are also important determinants of suicide intentions, while the level of neurological disability itself is not a risk factor for suicide (Feinstein, 2002). Therefore, experts agreed that the only step to prevent suicide is to identify and treat the psychological and social disorders of multiple sclerosis patients (Goldman Consensus Group, 2005).

Quality of life is one of the main considerations that should be taken into account in clinical studies for patients with Multiple Sclerosis (Rieckmann et al., 2015). Multiple sclerosis is associated with many psychological and mental disorders that affect the quality of life of patients, as symptoms appear suddenly and with repeated appearances, they reduce patients' abilities and reduce their quality of life (Chwastiak \& Ehde, 2007). Therefore, therapists face different challenges in dealing with patients, and due to the interest of specialists in improving the quality of life of patients they used measures related to the quality of life (Nery, 2016). Results revealed that fatigue is the main reason that prevents them from participating in various activities, which in turn leads to a decrease in their quality of life (Nery, 2016).

There are few studies that focused on the quality of life for multiple sclerosis patients in Arab countries for instance; Saudi Arabia, Iran, Khartoum, and Kuwait, which reported the importance of taking into consideration the quality of life of multiple sclerosis patients (Rezapour et al., 2017; Alhazzani et al., 2018; Ibrahim et al., 2019; Alshubaili et al., 2007). Up to the researchers' knowledge, a few studies were conducted to assess the quality of life in general for multiple sclerosis patients in Jordan (Aburub et al., 2020; Hyarat et al., 2019; Al-Sharman et al., 2018). Accordingly, this study aimed to identify the mental health quality of life among patients with multiple sclerosis in Jordan. Consequently, the findings of this study can provide the level of mental health associated with quality of life among multiple sclerosis patients. Furthermore, provide a direction for psychotherapist to identify the factors that negatively affect multiple sclerosis patients' mental health quality of life.

\section{Material and Methods}

A descriptive quantitative design was used in this study. A total of $(\mathrm{N}=100)$ Multiple Sclerosis patients were randomly selected by using convenience sampling from the Health Insurance Center in the capital Amman, Jordan. A self-reported questionnaire was used in this study, the demographic data form and the Multiple Sclerosis Quality of Life-54 (MSQOL-54) Scale. The demographic data form consisted of questions about: age in years, gender, stage of multiple scleroses, and physical activities.

The Multiple Sclerosis Quality of Life-54 (MSQOL-54) Scale consist of 54-item which generates 12 subscales along with two summary scores, and two additional single-item measures. The subscales are: physical function, role limitations-physical, role limitations-emotional, pain, emotional well-being, energy, health perceptions, social function, cognitive function, health distress, overall quality of life, and sexual function. The summary scores are the physical health composite summary and the mental health composite summary. The single item measures are satisfaction with sexual function and change in health. The response scale of the Quality of Life 54 Scale consists of various responses, with minimum response scale (2) and maximum response (10). Two 
summary scores the physical health and mental health can be derived from a weighted combination of scale scores.

The Multiple Sclerosis Quality of Life-54 (MSQOL-54) was translated to Arabic language using back translation following the WHO guidelines for translation. To ensure validity of the tool, it was judged and reviewed by a $(\mathrm{N}=5)$ of academic professors specialist in the subject of study. Cronbach's alpha was used to estimate the reliability of the sample of study. The Cronbach's alpha for the Arabic Multiple Sclerosis Quality of Life (MSQOL-54) was (.997). A pilot study was conducted on ( $\mathrm{N}=10)$ Multiple Sclerosis patients to ensure content validity.

\section{Results}

A total of $(\mathrm{N}=100)$ multiple sclerosis patients participated in the study. All the participants were categorized under the first stage of multiple sclerosis the relapsing-remitting multiple sclerosis (RRMS) stage. The majority of the sample was females $77 \%$. Nearly two-third of the sample did not participate in any physical activity $74 \%$ and only $26 \%$ of the sample participated in physical activity. Regarding age in years, more than two third of the sample $67 \%$ ranged between 20 to $<30$ years and $10 \%$ of the sample ranged between 40 to $<50$ years. Finally, the results revealed that QOL- Mental Health Composite among patients with multiple sclerosis was 33.9 \pm 33.6. It is present in Table 1.

Table 1. The Number of Individuals, Sum, Mean and Standard deviation for the QOL-Mental Health Composite.

\begin{tabular}{cccc}
\hline Outcome & N & Sum & M \pm SD \\
\hline QOL-Mental Health Composite & 100 & 3397.8 & $33.978 \pm 33.6392$ \\
\hline
\end{tabular}

Note. $\mathrm{N}=$ Number of Individuals; $\mathrm{M}=$ Mean, $\mathrm{SD}=$ Standard Deviation.

Independent t-test was conducted to compare the QOL-mental health scores for males and females. There was no significant difference in score for male and females $\mathrm{p}=.874$. It is present in Table 2.

Table 2. Independent t-test for the quality of life in terms of mental health according to gender variable for multiple sclerosis patients

\begin{tabular}{ccccccc}
\hline Outcome & Group & $\mathrm{N}$ & $\mathrm{M} \pm \mathrm{SD}$ & $\mathrm{df}$ & $\mathrm{t}$ & Sig (2-tailed) \\
\hline \multirow{2}{*}{ QOL-Mental Health } & Male & 23 & $34.959 \pm 33.1593$ & \multirow{2}{*}{98} & .159 & .874 \\
& Female & 77 & $33.684 \pm 33.9910$ & & &
\end{tabular}

Note. $\mathrm{N}=$ Number of Individuals; $\mathrm{M}=$ Mean, $\mathrm{SD}=$ Standard Deviation, $\mathrm{df}=$ degree of freedom, $\mathrm{t}=\mathrm{t}-\mathrm{value}$, Sig (2tailed $)=$ level of statistically significance at the level of $(\alpha \leq 0.05)$.

Moreover, independent t-test was conducted to compare the QOL-mental health scores for participants in physical activity and non-participants in physical activity. There was a significant difference in scores for participants and non-participants in physical activity $\mathrm{p}=.000$. It is present in Table 3.

Table 3. Independent t-test for the quality of life in terms of mental health according to physical activity variable for multiple sclerosis patients

\begin{tabular}{ccccccc}
\hline Outcome & Group & $\mathrm{N}$ & $\mathrm{M} \pm \mathrm{SD}$ & $\mathrm{df}$ & $\mathrm{t}$ & Sig (2-tailed) \\
\hline QOL-Mental & Participants in physical activity & 26 & $80.696 \pm 20.8083$ & \multirow{2}{*}{98} & \multirow{2}{*}{14.582} & \multirow{2}{*}{.000} \\
Health & Non-participants in physical activity & 74 & $17.563 \pm 18.3261$ & & & \\
\hline
\end{tabular}

Note. $\mathrm{N}=$ Number of Individuals; $\mathrm{M}=$ Mean, $\mathrm{SD}=$ Standard Deviation, $\mathrm{df}=$ degree of freedom, $\mathrm{t}=\mathrm{t}$-value, Sig (2tailed $)=$ level of statistically significance at the level of $(\alpha \leq 0.05)$.

Finally, a one-way between-groups analysis of variance (ANOVA) was conducted to explore the impact of age in years on the level of QOL mental health. There was no significant difference in QOL mental health scores for the age groups $\mathrm{p}=.165$. It is present it Table 4 . 
Table 4. ANOVA for the quality of life in terms of mental health according to age in year's variable for multiple sclerosis patients

\begin{tabular}{ccccccc}
\hline \multicolumn{2}{c}{ QOL- Mental Health } & Sum of Squares & Mean Square & df & F & Sig \\
\hline \multirow{3}{*}{ Age in years } & Between Groups & 4089.619 & 2044.810 & 2 & & \multirow{2}{*}{165} \\
& Within groups & 107938.296 & 1112.766 & 97 & 1.838 & \\
& Total & 112027.915 & & 99 & & \\
\hline
\end{tabular}

Note. $\mathrm{df}=$ degree of freedom; F= F-Statistic, Sig= level of statistically significance at the level of $(\alpha \leq 0.05)$.

\section{Discussion}

The results of this study revealed that the quality of life of multiple sclerosis patients in terms of mental health is low, where was below 50. Multiple sclerosis is a disease that is associated with several health complications related to consciousness, memory and mental processes. It affects patient's mental health negatively, as one of the main causes of neurological disability in youth (Compston \& Coles, 2008). Multiple sclerosis impairs the quality of their lives, their psychological symptoms such as depression, anxiety and stress due to the chronic nature of the disease and lack of treatment (Salehpoor et al., 2014). Thus, treating the quality of patients' mental life is vital in medical care and patient rehabilitation (Patti et al., 2003).

The researchers explain the reason behind mental decline in the quality of life among multiple sclerosis patients was due to fatigue. More than $90 \%$ of people with multiple sclerosis suffer from fatigue (Lauren \& Krupp, 2010). A study conducted in Jordan consisted of 80 multiple sclerosis patients indicated that all of the study sample have suffered from fatigue (Abu Maloh \& Alnahar, 2020). Hence, patients' life satisfaction depends on their evaluation of their quality of life, where the most important is their ability to meet their needs and requirements. The fatigue that is associated with multiple sclerosis plays a prominent role in changing the quality of life of patients, as it negatively affects their daily practices and their ability to cope with other symptoms (Lauren \& Krupp. 2010). Furthermore, fatigue was found to be the main cause for profound social and functional life of patients with multiple sclerosis (Hemmett et al., 2004). A study indicated a correlation between fatigue associated with multiple sclerosis, disease severity, and quality of life for MS patients (Khalil et al., 2019).

The results of our study revealed that the mental health quality of life for multiple sclerosis patients was $33.9 \pm$ 33.6. Some studies have shown the quality of life for multiple sclerosis patients in terms of mental health, one study revealed results indicated that the quality of life for multiple sclerosis patients in terms of mental health was $64.8 \pm 21.0$ (Benedicta et al., 2005). Another study, reported that the quality of life for multiple sclerosis patients in terms of mental health was $59.5 \pm 21.4$ (Rezapour et al., 2017). Finally, a study conducted in Al-Khartoum showed that the quality of life for multiple sclerosis patients in terms of mental health was $61.2 \pm$ 22.4 (Ibrahim et al., 2019).

The current study results also revealed a non- significant difference in the quality of life of multiple sclerosis patients in terms of mental health between males and females This result complies with some studies where the results showed there were no significant difference in the quality of life for multiple sclerosis patients in terms of mental health between male and female (Idiman et al., 2006; Albuquerquea et al., 2015; Rezapour et al., 2017; Janardhan \& Bakshi, 2002). On the other hand, one study contradicted the results which showed that the quality of life among females with multiple sclerosis is lower than among males (Sahebalzamani et al., 2012). Although, the incidence rate of this disease is higher among females (Pugliatti et al., 2006). However, multiple sclerosis is one of the mysterious diseases, as the cause of the disease and its treatment have not discovered yet. Multiple sclerosis is a chronic autoimmune disease that destroys nerves and melanin, the cause of the disease is unknown (Mold et al., 2018). Having multiple sclerosis is a real crisis for the patient as a result of the disability and restrictions associated with the disease, which negatively affects the quality of patient's mental health for male and female. Multiple sclerosis has no cure and negatively affects the patients' emotional, social and economic health (Browne et al., 2014).

The results of our study showed that there were no significant differences in the quality of life for patients with multiple sclerosis in terms of mental health related to age. Some studies supported our results, where they showed no significant differences in the quality of life for multiple sclerosis patients according to age (Idiman et al., 2006; Janardhan \& Bakshi, 2002). In contrast, some studies contradicted our results which their results indicated a significant difference in the quality of life for multiple sclerosis patients according to age for the group of less than 40 years old (Ibrahim et al., 2019; Salehpoor et al., 2012.). 
The researchers attribute this to the fact that the entire study sample was afflicted with the first type of MS, which is "Relapsing-Remitting Multiple Sclerosis", where the patient relapses and the symptoms appear for a while, and then the body begins the repair phase. Multiple sclerosis has multiple forms with the present of new symptoms appearing in the form of sporadic attacks, and between attacks the symptoms may disappear completely or accumulate over time especially with the progression of the disease (Jalali-Farahani et al., 2017). Hence, the medicine provided for this type in particular reduces the number of attacks and scars in the brain; therefore the pathological effects and the severity of the symptoms are converging. There is a group of drugs for the treatment of the first type of multiple sclerosis the "Relapsing-Remitting Multiple Sclerosis" which works by reducing the number of attacks and scars in the brain (Food and Drug Administration [FDA], 2011). Among these drugs AVONEX, BETA SERON, EXTAVIA, REBIF and GLATIRAMER ACETATE which are given by injection, as they are considered to be the primary treatment (FDA, 2011). Experts recommend these drugs upon diagnosis of the disease, while additional treatment includes other drugs like (NATALIZUMB and MITOXANTRONE) (FDA, 2011).

The results of this study showed that the mental health quality of life for multiple sclerosis patients is higher for patients who engage in physical activities. Some studies supported our results; one study reported that the quality of life for multiple sclerosis patients practicing physical activities is better than the non- practicing physical activity patients (Stroud \& Minahan, 2009). Another study reported that physical activities helped in reducing fatigue among multiple sclerosis patients (Abu Maloh \& Alnahar, 2020). In contrast, one study contradicted our results which their results indicated no significant difference in the quality of life for multiple sclerosis patients between practitioners and non-practitioners of water exercise (Bahari et al., 2015).

Due to their fear of exacerbating of the disease symptoms, patients with multiple sclerosis reduce their activities most often (Dalgas et al., 2008). But this in turn will aggravate their disability, lack of fitness, muscle weakness, walking deformities, and a decrease in their quality of life (Pilutti et al., 2014). However, the practice of physical activities is considered to be an important therapy for most multiple sclerosis patients as it relieves symptoms associated with the disease which contributes to enhance their quality of mental health. Physical activities should be considered as a safe and effective way to rehabilitate patients with multiple sclerosis, an individualized program supervised by a specialist can improve their fitness, modifiable disabilities, and their quality of life (Halabchi et al., 2017).

Moreover, low to moderate intensity of aerobic activities leads to the improvements in mood and depression measures among multiple sclerosis patients (Sandoval, 2013). Furthermore, the practice of physical activities also delays the onset of fatigue associated with multiple sclerosis through the development of patients' fitness, which gives them better opportunities to practice their daily activities. A study conducted in Jordan revealed that there is a positive effect of physical activities on fatigue associated with multiple sclerosis (Abu Maloh \& Alnahar, 2020). Practicing the appropriate physical activities has several benefits for MS patients, of which; increasing muscle strength, improving aerobic capacity, reducing fatigue, and improving perception and cognition, balance and the patients quality of life (Motl \& Sandroff, 2015).

\section{Conclusion}

Multiple sclerosis patients' have a low quality of life in terms of mental health. Moreover, there were no significant differences in the mental health of multiple sclerosis patients according to the gender and age in year's variables. In addition, practicing physical activities have a positive effect on the quality of mental health among multiple sclerosis patients.

\section{Acknowledgments}

This research did not receive any specific grant from funding agencies in the public, commercial, or not-for-profit sectors.

\section{References}

Abu Maloh, D., \& Alnahar, H. (2020). Sports Practice Role and Effect on Decreasing Fatigue in Multiple Sclerosis Patients. Dirasat Journals, 47(4), 1-10. Retrieved from https://journals.ju.edu.jo/DirasatEdu/article/view/108046

Aburub, A. S., Khalil, H., Al-Sharman, A., \& El-Salem, K. (2021). Measuring quality of life and identifying what is important to Jordanian living with multiple sclerosis using the Arabic version of the patient-generated index. Physiotherapy research international: The journal for researchers and clinicians in physical therapy, 26(2), e1893. https://doi.org/10.1002/pri.1893

Albuquerquea, C., Geraldob, A., Martinsa, R., \& Ribeiroa, O. (2015). Quality of life of people with multiple 
sclerosis: Clinical and psychosocial determinants. Procedia - Social and Behavioral Sciences, 171, 359-365. https://doi.org/10.1016/j.sbspro.2015.01.133

Aldahri, S. (2005). Principals of Psychological Health (1st ed.). Jordan: Dar Wael.

Alhams, S. (2010). Anxiety of Birth Among Mothers in Southern Governorates of Gaza Strip and its Relation to Life's Quality (Unpublished Master Thesis). Islamic University. Gaza.

Alhazzani, A. A., Alqahq1atani, M. S., Alahmari, M. S., Asiri, M. A., Alamri, N. M., Sarhan, L. A., Alkhashrami, S. S., \& Asiri, A. A. (2018). Quality of life assessment among multiple sclerosis patients in Saudi Arabia. Neurosciences (Riyadh, Saudi Arabia), 23(2), 140-147. https://doi.org/10.17712/nsj.2018.2.20170335

Alkhulaifi, I. (2000). Psychological Counseling as an Entry Point for Achieving Quality of Life from a Self-dealing Perspective "An Evaluation of the Impact of Behavioral Control Counseling Courses". Journal of Faculty of Education of Benha, (20). Retrieved from http://search.mandumah.com/Record/755288

Almarzouqi, J. (2008). Psychological Diseases and Their Relation to Diabetes (1st ed.). Jordan: Dar AlIman for Publishing and Distribution.

Al-Sharman, A., Khalil, H., Nazzal, M., Al-Sheyab, N., Alghwiri, A., El-Salem, K., \& AlDughmi, M. (2018). Living with multiple sclerosis: A Jordanian perspective. Physiotherapy research international: The journal for researchers and clinicians in physical therapy, 23(2), e1709. https://doi.org/10.1002/pri.1709

Alshubaili, A. F., Ohaeri, J. U., Awadalla, A. W., \& Mabrouk, A. A. (2007). Quality of life in multiple sclerosis: A Kuwaiti MSQOL-54 experience. Acta Neurologica Scandinavica, 117(6), 384-392. https://doi.org/10.1111/j.1600-0404.2007.00960.x

Asadi-Lari, M., Tamburini, M., \& Gray, D. (2004). Patients' needs, satisfaction, and health related quality of life: towards a comprehensive model. Health and quality of life outcomes, 2, 32. https://doi.org/10.1186/1477-7525-2-32

Bahari, F., Sanatkaran, A., \& Pashang, S. (2015). The Effects of Water Exercises on the Quality of Life in Patients with Multiple Sclerosis. ASJ, 12(3), 121-128. Retrieved from http://anatomyjournal.ir/article-1-115-en.html

Benedict, R. H., Wahlig, E., Bakshi, R., Fishman, I., Munschauer, F., Zivadinov, R., \& Weinstock-Guttman, B. (2005). Predicting quality of life in multiple sclerosis: accounting for physical disability, fatigue, cognition, mood disorder, personality, and behavior change. Journal of the neurological sciences, 231(1-2), 29-34. https://doi.org/10.1016/j.jns.2004.12.009

Bialuhina, V., Belugina, I., Azarova, L., Siatkovskaia, N., Siatkovski, V., \& Jagovdik, N. (2017). The role of psychotherapy in improving the quality of life and social rehabilitation of patients with Psoriasis. European Psychiatry, 41, S773. https://doi.org/10.1016/j.eurpsy.2017.01.1460

Browne, P., Chandraratna, D., Angood, C., Tremlett, H., Baker, C., Taylor, B. V., \& Thompson, A. J. (2014). Atlas of Multiple Sclerosis 2013: A growing global problem with widespread inequity. Neurology, 83(11), 1022-1024. https://doi.org/10.1212/wnl.0000000000000768

Chwastiak, L. A., \& Ehde, D. M. (2007). Psychiatric issues in multiple sclerosis. The Psychiatric clinics of North America, 30(4), 803-817. https://doi.org/10.1016/j.psc.2007.07.003

Compston, A., Confaverux, C., Lassman, H., Mc Donald, I., Miller, D., Noseworty, J., Smith, K., \& Wekerle, H. (2006). McAlpines multiple sclerosis (4th ed.). Philadelphia: Churchill Livingstone/Elsevier.

Compston, A., \& Coles, A. (2008). Multiple sclerosis. The Lancet, 372(9648), 1502-1517. https://doi.org/10.1016/s0140-6736(08)61620-7

Cook, S. C., Schwartz, A. C., \& Kaslow, N. J. (2017). Evidence-Based Psychotherapy: Advantages and Challenges. Neurotherapeutics: The journal of the American Society for Experimental NeuroTherapeutics, 14(3), 537-545. https://doi.org/10.1007/s13311-017-0549-4

Dalgas, U., Stenager, E., \& Ingemann-Hansen, T. (2008). Multiple sclerosis and physical exercise: recommendations for the application of resistance-, endurance- and combined training. Multiple sclerosis (Houndmills, Basingstoke, England), 14(1), 35-53. https://doi.org/10.1177/1352458507079445

FDA. (2011). Approves first oral drug to reduce MS relapses; September 22, 2010. Retrieved from http://www.fda.gov/NewsEvents/Newsroom/PressAnnouncements/ucm226755.htm

Feinstein, A. (1997). Multiple sclerosis, depression, and suicide. BMJ (Clinical research ed.), 315(7110), 
691-692. https://doi.org/10.1136/bmj.315.7110.691

Feinstein, A. (2002). An examination of suicidal intent in patients with multiple sclerosis. Neurology, 59(5), 674-678. https://doi.org/10.1212/wnl.59.5.674

Goldman Consensus Group. (2005). The Goldman Consensus statement on depression in multiple sclerosis. Multiple sclerosis (Houndmills, $\quad$ Basingstoke, $\quad$ England), $11(3), \quad 328-337$. https://doi.org/10.1191/1352458505ms1162oa

Halabchi, F., Alizadeh, Z., Sahraian, M. A., \& Abolhasani, M. (2017). Exercise prescription for patients with multiple sclerosis; potential benefits and practical recommendations. BMC neurology, 17(1), 185. https://doi.org/10.1186/s12883-017-0960-9

Hemmett, L., Holmes, J., Barnes, M., \& Russell, N. (2004). What drives quality of life in multiple sclerosis?. QJM: Monthly Journal of the Association of Physicians, 97(10), 671-676. https://doi.org/10.1093/qjmed/hch105

Hyarat, S. Y., Subih, M., Rayan, A., Salami, I., \& Harb, A. (2019). Health Related Quality of Life Among Patients With Multiple Sclerosis: The Role of Psychosocial Adjustment to Illness. Archives of psychiatric nursing, 33(1), 11-16. https://doi.org/10.1016/j.apnu.2018.08.006

Ibrahim, E. A. A. E., Gassoum, A., \& IshagAgib, I. E. I. (2019). Quality of life among Sudanese patients with multiple sclerosis in Khartoum state using (MSQoL-54) questionnaire. BMC Res Notes, 12, 533. https://doi.org/10.1186/s13104-019-4565-9

Idiman, E., Uzunel, F., Ozakbas, S., Yozbatiran, N., Oguz, M., Callioglu, B., Gokce, N., \& Bahar, Z. (2006). Cross-cultural adaptation and validation of multiple sclerosis quality of life questionnaire (MSQOL-54) in a Turkish multiple sclerosis sample. Journal of the neurological sciences, 240(1-2), 77-80. https://doi.org/10.1016/j.jns.2005.09.009

Jalali-Farahani, S., Amiri, P., Bakht, S., Shayeghian, Z., Cheraghi, L., \& Azizi, F. (2017). Socio-Demographic Determinants of Health-Related Quality of Life in Tehran Lipid and Glucose Study (TLGS). International journal of endocrinology and metabolism, 15(4), e14548. https://doi.org/10.5812/ijem.14548

Janardhan, V., \& Bakshi, R. (2002). Quality of life in patients with multiple sclerosis: the impact of fatigue and depression. Journal of the neurological sciences, 205(1), 51-58. https://doi.org/10.1016/s0022-510x(02)00312-x

Keyes, C., Fredrickson, B., Park, N., \& Keyes, C. (2012). Positive Psychology and the Quality of Life. https://doi.org/10.1007/978-94-007-2421-1_5

Kfafi, A., \& Ala’ Aldeen, J. (2006). Rehabilitation Psychology Enclopedia (1st ed.). Egypt: Dar Al feker Al Arabi.

Khalil, H., Al-Shorman, A., Alghwiri, A., Abdo, N., El-Salem, K., Shalabi, S., \& Aburub, A. (2019). Cross Cultural Adaptation and Psychometric Evaluation of an Arabic Version of the Modified Fatigue Impact Scale in People with Multiple Sclerosis, Multiple Sclerosis and Related Disorders. https://doi.org/10.1016/j.msard.2019.101878.

Korostil, M., \& Feinstein, A. (2007). Anxiety disorders and their clinical correlates in multiple sclerosis patients. Multiple sclerosis (Houndmills, $\quad$ Basingstoke, $\quad$ England), $\quad 13(1), \quad 67-72$. https://doi.org/10.1177/1352458506071161

Lauren, B., \& Krupp, M. D. (2010). MS Society of Canada educational Series, Living well with MS: managing fatigue. Retrieved from https://mssociety.ca/en/pdf/livingWell.pdf

Mold, M., Chmielecka, A., Rodriguez, M., Thom, F., Linhart, C., King, A., \& Exley, C. (2018). Aluminium in Brain Tissue in Multiple Sclerosis. International journal of environmental research and public health, 15(8), 1777. https://doi.org/10.3390/ijerph15081777

Motl, R. W., \& Sandroff, B. M. (2015). Benefits of Exercise Training in Multiple Sclerosis. Current neurology and neuroscience reports, 15(9), 62. https://doi.org/10.1007/s11910-015-0585-6

Nery, M. (2016). Multiple Sclerosis and Wellness: How Self-Compassion Influences Physical Activity and Health-Related Quality of Life (Unpublished doctoral dissertation). Oregon State University, Corvallis, Oregon.

Noseworthy, J. H., Lucchinetti, C., Rodriguez, M., \& Weinshenker, B. G. (2000). Multiple sclerosis. The New 
England journal of medicine, 343(13), 938-952. https://doi.org/10.1056/NEJM200009283431307

Patti, F., Cacopardo, M., Palermo, F., Ciancio, M. R., Lopes, R., Restivo, D., \& Reggio, A. (2003). Health-related quality of life and depression in an Italian sample of multiple sclerosis patients. Journal of the neurological sciences, 211(1-2), 55-62. https://doi.org/10.1016/s0022-510x(03)00040-6

Pilutti, L. A., Platta, M. E., Motl, R. W., \& Latimer-Cheung, A. E. (2014). The safety of exercise training in multiple sclerosis: a systematic review. Journal of the neurological sciences, 343(1-2), 3-7. https://doi.org/10.1016/j.jns.2014.05.016

Pugliatti, M., Rosati, G., Carton, H., Riise, T., Drulovic, J., Vécsei, L., \& Milanov, I. (2006). The epidemiology of multiple sclerosis in Europe. European journal of neurology, 13(7), 700-722. https://doi.org/10.1111/j.1468-1331.2006.01342.x

Raune, D., Kuipers, E., \& Bebbington, P. E. (2004). Expressed emotion at first-episode psychosis: investigating a carer appraisal model. The British journal of psychiatry: The journal of mental science, 184, 321-326. https://doi.org/10.1192/bjp.184.4.321

Rezapour, A., Almasian Kia, A., Goodarzi, S., Hasoumi, M., Nouraei Motlagh, S., \& Vahedi, S. (2017). The impact of disease characteristics on multiple sclerosis patients' quality of life. Epidemiology and health, 39, e2017008. https://doi.org/10.4178/epih.e2017008

Rieckmann, P., Boyko, A., Centonze, D., Elovaara, I., Giovannoni, G., Havrdová, E., ... Vermersch, P. (2015). Achieving patient engagement in multiple sclerosis: A perspective from the multiple sclerosis in the 21st Century Steering Group. Multiple sclerosis and related disorders, 4(3), 202-218. https://doi.org/10.1016/j.msard.2015.02.005

Sadovnick, A. D., Eisen, K., Ebers, G. C., \& Paty, D. W. (1991). Cause of death in patients attending multiple sclerosis clinics. Neurology, 41(8), 1193-1196. https://doi.org/10.1212/wnl.41.8.1193

Sahebalzamani, M., Zamiri, M., \& Rashvand, F. (2012). The effects of self-care training on quality of life in patients with multiple sclerosis. Iranian journal of nursing and midwifery research, 17(1), 7-11. PMID: 23493483; PMCID: PMC3590698.

Salehpoor, G., Hosseininezhad, M., \& Rezaei, S. (2012). A preliminary path analysis: Effect of psychopathological symptoms, mental and physical dysfunctions related to quality of life and body mass index on fatigue severity of Iranian patients with multiple sclerosis. Iranian journal of neurology, 11(3), 96-105. PMID: 24250873; PMCID: PMC3829253.

Salehpoor, G., Rezaei, S., \& Hosseininezhad, M. (2014). Quality of life in multiple sclerosis (MS) and role of fatigue, depression, anxiety, and stress: A bicenter study from north of Iran. Iranian journal of nursing and midwifery research, 19(6), 593-599.PMID: 25558256; PMCID: PMC4280723.

Sandoval, A. E. (2013). Exercise in multiple sclerosis. Physical medicine and rehabilitation clinics of North America, 24(4), 605-618. https://doi.org/10.1016/j.pmr.2013.06.010

Slade, M. (2010). Mental illness and well-being: The central importance of positive psychology and recovery approaches. BMC health services research, 10, 26. https://doi.org/10.1186/1472-6963-10-26

Stenager, E. N., Koch-Henriksen, N., \& Stenager, E. (1996). Risk factors for suicide in multiple sclerosis. Psychotherapy and psychosomatics, 65(2), 86-90. https://doi.org/10.1159/000289052

Stroud, N. M., \& Minahan, C. L. (2009). The impact of regular physical activity on fatigue, depression and quality of life in persons with multiple sclerosis. Health and quality of life outcomes, 7, 68. https://doi.org/10.1186/1477-7525-7-68

\section{Copyrights}

Copyright for this article is retained by the author(s), with first publication rights granted to the journal.

This is an open-access article distributed under the terms and conditions of the Creative Commons Attribution license (http://creativecommons.org/licenses/by/4.0/). 